\title{
Suitability Analysis of Implementing a Fuel Cell on a Multirotor Drone
}

\author{
Jørgen Apeland ${ }^{1,2, \star}$, Dimitrios Pavlou', Tor Hemmingsen¹
}

Apeland J (D) https: / / orcid.org/0000-0001-7647-2942

Pavlou D (D) https://orcid.org/0000-0002-9522-583X

Hemmingsen T (D) https: / / orcid.org/0000-0002-5636-5792
How to cite

Apeland J, Pavlou D, Hemmingsen T. Suitability Analysis of Implementing a Fuel Cell on a Multirotor Drone. J Aerosp Tecnol Manag, 12 e3220. https://doi.org/10.5028/jatm. v12.1172

ABSTRACT: Increased flight time of multirotor drones is a key enabler for further adoption and industrial use of drones. A model for analyzing the performance of a fuel cell hybrid system for a multirotor drone is presented and applied for a case with an X8 multirotor drone with a maximum take-off mass of $25 \mathrm{~kg}$. Endurance is the main performance parameter, and the model can be used to quantify the relative performance between different power sources. The model aims to determine if a specific hybrid fuel cell system is a viable option for a given multirotor drone and if it will provide better endurance than when powered by batteries. The model can also be used in system optimization and sensitivity analysis. In a case study, a fuel cell hybrid system with a $7.2 \mathrm{~L}$ cylinder with hydrogen at 300 bar is found to increase the flight time by 43 minutes (+76\%) from the currently used LiPo-batteries. A plot identifies the energy system mass threshold for when the fuel cell hybrid system gives better endurance than batteries to be $7.3 \mathrm{~kg}$. Based on current technology status, the cost of a fuel cell hybrid system is about 12 times that of LiPo-batteries.

KEYWORDS: PEM fuel cell; Hybrid system; Multirotor drone; Endurance model

\section{INTRODUCTION}

There is an increasing use of unmanned aircraft systems for industrial applications as cost-efficient, safe, and time-saving alternatives to traditional methods. One of the main restrictions for further adoption of multirotor drones is the limited endurance. The typical flight time of a multirotor drone powered by LiPo-batteries is $20-50$ minutes. With operational safety margins, the effective mission time is generally low, which limits the operational range and possible area coverage.

Fuel Cell Hybrid Systems (FCHS) have emerged as one viable option to extend endurance on multirotor drones. They consist of a fuel cell that provides a continuous power and a hybrid battery to handle transient loads and power peaks. Such systems can provide a higher specific energy than batteries. Compared to internal combustion engines, fuel cells offer less maintenance, no vibrations, and more silent operation.

Early research efforts have mainly focused on fixed-wing Unmanned Aerial Vehicles (UAV). Bradley et al. (2009b) presents the fundamentals of fuel cell powerplant design considerations for small UAVs. One of the first demonstrator projects was in 2003, with more than ten projects in the following years (Bradley et al., 2009a). Gong and Verstraete (2017) presents some of the later developments for fuel cell powered UAVs.

Multirotor drones have more power-intensive propulsion systems than fixed-wing UAVs and a more dynamic power profile. As the dynamic response of fuel cells is quite poor, hybrid batteries are essential for the maneuverability. Poor hybrid management

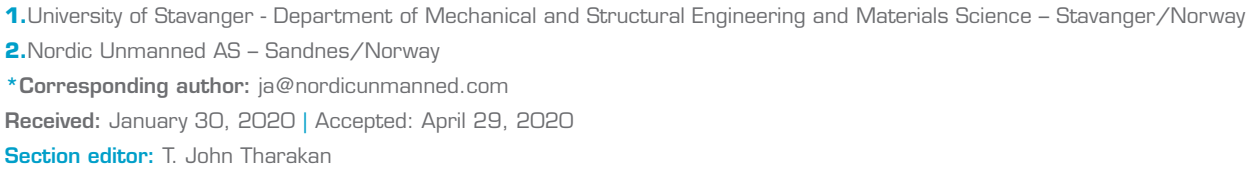


can lead to membrane dehydration and fuel starvation (Verstraete et al., 2014; Nishizawa et al., 2013). Boukoberine et al. (2019) provides an overview of various power sources and energy management systems for multirotor drones.

There are some commercially available fuel cell systems and fuel cell powered drones. Intelligent Energy provides $650 \mathrm{~W}$ and $800 \mathrm{~W}$ fuel cell modules that can be integrated on multirotor drones (Barrett, 2018b), and in 2019 they announced a more powerful $2.4 \mathrm{~kW}$ fuel cell module (Barrett, 2019b). HES provides a range of lightweight fuel cells and the Hycopter, a fuel cell powered drone which has prompted interest from the Dubai Police (Barrett, 2018a; Barrett, 2019a). In 2017, the French Air Force purchased H2QUAD 1000 drones from EnergyOR, capable of carrying a 1 kg payload for 2 hours (Barrett, 2017). The performance of fuel cell powered drones is continuously improved, and in 2019 project Rachel achieved an endurance of 70 minutes with $5 \mathrm{~kg}$ payload and a take-off mass of $20 \mathrm{~kg}$. A project by Metavista used a $650 \mathrm{~W}$ Intelligent Energy FC to carry out a 10 hours and 50 minutes flight using liquid hydrogen storage (Barrett, 2019c).

Due to the high power requirements and the need for larger batteries, fuel cell hybrid systems for multirotor drones are more massive than for fixed-wing UAVs. Thus, FCHS is not a viable option for all multirotor drones. This paper presents a model for assessing whether a fuel cell hybrid system is a viable option as a power source on a multirotor drone, and if it will provide a better performance than when powered by batteries as the primary power source.

The model uses endurance as the primary performance parameter, and the intention is that it can be used as a tool in the early stages of concept development and preliminary design to identify the best power source for a specific multirotor drone. By quantifying the performance of various system configurations, the model can also be used in optimization and sensitivity analysis.

The model assumes an open cathode proton exchange membrane (PEM) fuel cell with compressed hydrogen as fuel. This is one of the most developed and commercially available lightweight fuel cell types available. The model assumes that the system is designed with adequate margins to compensate for degradation mechanisms and environmental effects when operated within the defined operational envelope, and is not considered numerically.

First, the endurance model and the sub-models for calculation of energy, mass, and propulsion power consumption are presented. A case study of a fuel cell hybrid system on a multirotor drone with a maximum take-off mass of $25 \mathrm{~kg}$ is carried out, and the validity, potential improvements, and further research are outlined.

\section{ANALYTIC MODELS}

\section{ENDURANCE}

The basic equation for flight endurance is:

$$
t_{e}=\frac{E}{P}
$$

where $E$ is the available energy, $P$ is the power consumption, and $t_{e}$ is the endurance. Using this equation, the performance of different energy systems can be compared. By using endurance as the basis for comparison, the total mass of the energy system and its effect on the power consumption is considered. As it is a theoretical comparison using all the available energy for propulsion and assuming static hovering, no transient effects from maneuvering and dynamic effects on the efficiency are considered. However, the relative gross endurance is considered to give a reasonable indication of the relative performance of a multirotor drone with different power sources. The sub-models for estimating the energy, mass, and power consumption related to batteryand fuel cell based power sources are provided below.

\section{SPECIFIC ENERGY}

The specific energy $\varepsilon_{S}$ of a power source is a gravimetric performance indicator, specifying the amount of energy $E$ stored per unit of mass $m$ : 


$$
\varepsilon_{S}=\frac{E}{m}
$$

This is an important parameter when comparing different power sources for multirotor drones, because the power consumption can be quite weight sensitive. Thus, the aim is to store as much energy possible, for as low weight possible. In general, a power source with a higher specific energy will give a better endurance. However, if there is a difference in the total mass of the power source, the endurance should be used as basis for comparison to capture and quantify the impact on the propulsion power.

\section{SUB-MODELS FOR ENERGY AND ASSOCIATED MASS}

\section{BATTERY}

The battery capacity $E_{\text {batt }}$ and weight $m_{\text {batt }}$ can be adapted from the battery specifications, or it can be calculated from Eq. (3) using the specific energy $\varepsilon_{S}$ :

$$
E_{b a t t}=\varepsilon_{s} \cdot m_{b a t t} \cdot \eta_{D O D}
$$

The specific energy relates to the battery chemistry. The most common battery type for multirotor drones are LiPo-batteries, which typically have a specific energy of $180 \mathrm{Wh} \cdot \mathrm{kg}^{-1}$. The depth of discharge $\eta_{D O D}$ of the battery affects the cycle life, as investigated by Dogger et al. (2011). A $\eta_{D O D}$ of $80 \%$ is considered a deep discharge (Mi and Masrur, 2018a) and by exceeding this, the batteries can experience permanent damage and limited cycle life. This aspect is important to consider when comparing power sources, so that they are compared by the amount of effective energy that can be used.

Batteries are simple in use, but they do have some inherent disadvantages such as performance degradation over time, reduction of capacity in cold weather, and that the capacity depends on the discharge rate (Dell et al., 2001). These factors can be considered numerically but are not included in this model.

\section{FUEL CELL HYBRID SYSTEM}

The hybrid system is characterized by the degree of hybridization $\beta_{\text {batt }}$, as calculated by Eq. (4). This is the relative average power distribution between the fuel cell and the battery. It is a design parameter that is used in system sizing and is related to system energy through the design endurance, efficiency, utilization factors, and safety margins. The range is from 0 to 1 , where 0 is only fuel cell power, and 1 is only battery power (Mi and Masrur, 2018b).

$$
\beta_{\text {Batt }}=\frac{P_{\text {batt }}}{P_{F C}+P_{\text {batt }}}
$$

The total energy of a fuel cell hybrid system $E_{F C H S}$ is the sum of the effective energy available from the FC system and hybrid battery:

$$
E_{F C H S}=E_{F C}+E_{h . b a t t}
$$

The mass of the fuel cell hybrid system $m_{F C H S}$ includes the mass of the fuel cell stack with plant balancing control electronics $m_{F C}$, the hydrogen cylinder with regulator and hose $m_{H_{2}}$, and the hybrid battery $m_{h \text {.batt }}$. The mass of hydrogen is only about $5 \%$ of the pressure vessel mass, and is neglected:

$$
m_{F C H S}=m_{F C}+m_{H_{2}}+m_{h . b a t t}
$$


When comparing power sources, it is important that all mass contributions associated with the systems are included to get a realistic comparison. The mass and power specifications of a fuel cell system is governed by what is commercially available.

\section{HYDROGEN ENERGY}

The effective electric energy from a fuel cell system $E_{F C}$ depends on the amount of hydrogen that is stored and the efficiency of the fuel cell. As a function of pressure and cylinder volume, it is:

$$
E_{F C}\left(p, V_{c y l}\right)=\rho_{\mathrm{H}_{2}}(p) \cdot V_{c y l} \cdot h_{\mathrm{H}_{2}} \cdot \eta_{F C} \cdot \eta_{\mathrm{H} 2}
$$

where the density of hydrogen $\rho_{\mathrm{H}_{2}}$ and the cylinder volume $V_{c y l}$ gives the hydrogen mass. The density of hydrogen as a function of pressure can be calculated according to the equation presented in (Lemmon et al., 2008), or be extracted from relevant tables. The specific enthalpy of hydrogen at the Lower Heating Value (LHV) is $h_{\mathrm{H}_{2}}=33.6 \mathrm{Wh} \cdot \mathrm{g}^{-1}$. By multiplying this with the hydrogen mass, the theoretical energy stored in the system is obtained. The fuel cell efficiency $\eta_{F C}$ is related to the cell voltage and can be assumed to be $50 \%$ (Larminie and Dicks, 2003). The last factor is the fuel utilization factor $\eta_{\mathrm{H} 2}$, representing the fact that not all hydrogen is used in the chemical reaction. This can be assumed to be 0.95 (Larminie and Dicks, 2003).

The cylinder volume and associated mass is given by commercially available options. A range of Class IV cylinders, carbon fiber wound vessels with a polymer liner, rated for 300 bar are listed in Table 1 . The specifications may vary between different manufacturers, and more lightweight cylinders are available. These might, however, have lower safety factors and a limited number of fill cycles.

Table 1. Properties for a series of lightweight Class IV cylinders from CTS. They are certified to store 300 bar hydrogen according to EN 12245 (CEN, 2002). A fuel cell efficiency of 50\% is assumed for the energy estimates.

\begin{tabular}{|c|c|c|c|c|c|}
\hline $\begin{array}{c}\text { Volume } \\
\text { [L] }\end{array}$ & $\begin{array}{c}\text { Cylinder Mass } \\
{[\mathrm{kg}]}\end{array}$ & $\begin{array}{c}\mathrm{H}_{2} \text { mass } \\
\text { [gram] }\end{array}$ & $\begin{array}{c}\text { Storage eff. } \\
{[\%]}\end{array}$ & $\begin{array}{c}\text { Specific Energy } \\
{\left[\mathbf{W h} \cdot \mathrm{kg}^{-1}\right]}\end{array}$ \\
\hline 2 & 1.2 & 41.7 & 3.5 & 700 & 584 \\
\hline 3 & 1.4 & 62.5 & 4.5 & 1050 & 750 \\
\hline 6 & 2.5 & 125.0 & 5.0 & 2101 & 840 \\
\hline 6.8 & 2.7 & 141.7 & 5.2 & 2381 \\
\hline 7.2 & 2.8 & 150.0 & 5.4 & 2521 & 800 \\
\hline 9 & 3.8 & 187.6 & 4.9 & 3151 & 829 \\
\hline
\end{tabular}

CTS - Composite Technical Systems

\section{HYBRID BATTERY}

The energy capacity of the hybrid battery as a function of the primary power source, the fuel cell system energy, can be calculated according to Eq. (8):

$$
E_{h . b a t t}\left(E_{F C}\right)=\frac{\beta_{b a t t}}{1-\beta_{b a t t}} \cdot E_{F C}+\left(t_{e m c} \cdot P_{F C H S}\right)
$$

where emergency power backup is calculated from the average power consumption $P_{F C H S}$ and the time required for an emergency landing $t_{e m c}$. By modifying Eq. (3), the mass of the hybrid battery $m_{h . b a t t}$ can be calculated according to Eq. (9):

$$
m_{h . b a t t}=\frac{E_{h . b a t t}}{\varepsilon_{S} \cdot \eta_{D O D}}
$$


The allowed depth of discharge must be considered to ensure that the required energy is available. Also, the calculated energy and mass are minimum values. In practice, a commercially available option that can provide the required energy and power (discharge rate) must be selected. Eq. (10) can be used to convert to the much used mAh battery definition. $U_{\text {nom }}$ is the nominal battery voltage:

$$
C_{m A h}=\frac{E_{h . b a t t}}{\eta_{D O D} \cdot U_{n o m}} \cdot 10^{3}
$$

\section{SUB-MODEL FOR POWER CONSUMPTION}

The relation between mass and propulsion power for the relevant multirotor drone must be established to capture the effect of changes in mass on the endurance. A simple approach to estimating this is presented below.

\section{MASS MODEL}

The take-off mass of a multirotor drone is:

$$
m_{T O M}=m_{E W}+m_{E}+m_{P L}
$$

where the empty weight $m_{E W}$ includes the airframe, electronics and the propulsion system. The mass of the energy system $m_{E}$ must include all components associated with the power source. For a fuel cell hybrid system, this mass is calculated according to Eq. (6). If relevant, the payload mass $m_{P L}$ can also be added. $m_{T O M}$ must be below the regulatory or design Maximum Take-off Mass (MTOM).

\section{PROPULSION POWER}

The propulsion power model for a single and coaxial rotor is based on one-dimensional momentum theory. The power required for a single isolated propeller in stationary hovering is provided in Eq. (12), as outlined by Leishman and Ananthan (2006):

$$
P_{\text {hover }}=\frac{T^{3 / 2}}{\sqrt{2 \cdot \rho_{\text {air }} \cdot A_{p r o p}}}
$$

where $A_{\text {prop }}$ is the propeller disc area, $T$ is the thrust in newtons, and $\rho_{\text {air }}$ is the density of air. For two propellers in a coaxial configuration, the required power is:

$$
P_{\text {coax }}=\kappa_{\text {int }} \frac{(2 T)^{3 / 2}}{\sqrt{2 \cdot \rho_{\text {air }} \cdot A_{p r o p}}}
$$

Because the lower propeller is affected by the wake of the upper propeller, a coaxial configuration is not $100 \%$ efficient. This is considered by the factor $\kappa_{i n t}$, which is presented in Table 2 for various boundary conditions. Most coaxial propeller configurations have an inefficiency somewhere in the range of 22 - $28 \%$. The actual efficiency will depend on many factors and can be identified by empirical data. 
Table 2. Inefficiency factor $\kappa_{\text {int }}$ for coaxial propeller configurations (Leishman and Ananthan, 2006)

\begin{tabular}{|c|c|}
\hline$\kappa_{i n t}$ & Boundary condition \\
\hline$\sqrt{2}=1.41$ & The coaxial rotors operate in the same plane, at the same thrust and/or torque. \\
\hline 1.281 & $\begin{array}{l}\text { The rotors operate at the same thrust. Lower rotor does not affect the wake contraction of the upper rotor, } \\
\text { but half the area operates in the slipstream velocity induced by the upper propeller. }\end{array}$ \\
\hline 1.219 & $\begin{array}{l}\text { The rotors operate at the same torque/power. Lower rotor does not affect the wake contraction of the upper } \\
\text { rotor, but half the area operates in the slipstream velocity induced by the upper propeller. }\end{array}$ \\
\hline 1 & Assumed to have ideal performance with no inefficiency. \\
\hline
\end{tabular}

The combined thrust $2 T$ of one coaxial pair should equal the take-off mass of the drone divided by the number of arms $n_{\text {arm' }}$, as expressed in Eq. (14):

$$
2 T=\frac{m_{\text {TOM }} \cdot g}{n_{\text {arm }}}
$$

Substituting Eq. (14) into Eq. (13), the generic equation for power consumption as a function of the take-off mass is:

$$
P_{\text {TOM }}\left(m_{\text {TOM }}\right)=n_{\text {arm }} \cdot \kappa_{\text {int }} \frac{\left(\frac{m_{\text {TOM }} \cdot g}{n_{\text {arm }}}\right)^{3 / 2}}{\sqrt{2 \cdot \rho_{\text {air }} \cdot A_{\text {prop }}}}
$$

By simplifying it for the case of a X8 configuration with four arms, the propulsion power as a function of the take-off mass becomes:

$$
P_{\text {ТОМ }}\left(m_{\text {ТОМ }}\right)=\kappa_{\text {int }} \frac{\left(m_{\text {TOM }} \cdot g\right)^{3 / 2}}{2 \sqrt{2 \cdot \rho_{\text {air }} \cdot A_{\text {prop }}}}
$$

Parasitic loads from the on-board electronics are assumed to be considered by the propulsion power. The model can be calibrated and validated by experiments using the exact propeller configuration. For relative comparisons, it is assumed to provide relevant results.

\section{ANALYSIS STEPS}

Six analysis steps are detailed using the above models. By following this approach, it should be clear if a fuel cell hybrid system is a viable option and improves endurance. It is assumed that a FC system and degree of hybridization is selected based on an expected average and peak power profile.

\section{SO: DEFINE BASIC PARAMETERS AND CALCULATE BATTERY BENCHMARK}

Collect the parameters listed in Table 3. From the battery specifications, the battery benchmark performance can be calculated:

I. The energy of the reference battery $E_{b a t t}$ can be identified from the battery specifications. The depth of discharge $\eta_{D O D}$ must be considered, as in Eq. (3). Use Eq. (10) to convert between mAh and Wh.

II. Calculate take-off mass using $m_{E}=m_{\text {batt }}$ in Eq. (11).

III. Calculate the propulsion power $P_{\text {ТОМ }}$ using Eq. (15) or Eq. (16).

IV. Calculate the battery reference endurance using Eq. (1). 


\section{S1: ENERGY IN FC-SYSTEM}

By knowing the cylinder volume and pressure, the available energy of the fuel cell system $E_{F C}$ is calculated from Eq. (7).

\section{S2: HYBRID BATTERY PROPERTIES}

From the calculated energy of the FC-system, the minimum energy required in the hybrid battery $E_{h . b a t t}$ and the associated mass $m_{\text {h.batt }}$ is calculated using Eq. (8) and Eq. (9).

\section{S3: CALCULATE SPECIFIC ENERGY}

All mass and energy components are known at this point, and the total mass $m_{F C H S}$ and energy of the fuel cell hybrid system $E_{F C H S}$ can be calculated according to Eq. (5) and Eq. (6). As an early indicator of the relative performance, the specific energy of the FCHS can be calculated using Eq. (2).

\section{S4: PROPULSION POWER}

The take-off mass $m_{\text {Том }}$, Eq. (11), is then used to calculate the associated propulsion power $P_{\text {Tом }}$ with Eq. (15) or Eq. (16).

\section{S5: ENDURANCE}

Knowing the propulsion power $P_{\text {TOM }}$ and the total energy $E_{F C H S}$ of the fuel cell hybrid system, the endurance can be calculated using Eq. (1).

\section{S6: ANALYZE THE RESULTS}

By analyzing the endurance for various systems, the relative performance is quantified and can be compared. This analysis approach can be followed to assess a) if a fuel cell hybrid system will give better flight time than when powered by batteries, and b) in sensitivity analysis and optimization of the FCHS.

\section{CASE STUDY: FCHS ON A 25 KG X8 MULTIROTOR DRONE}

\section{DRONE AND FUEL CELL HYBRID SYSTEM}

The endurance model from the previous chapter is applied to an X8 multirotor drone with a maximum take-off mass of $25 \mathrm{~kg}$ (Fig. 1). The fuel cell hybrid system consists of two A1000 Aerostak fuel cells, which combined can provide $2 \mathrm{~kW}$ of nominal power and a hybrid battery that is connected through a power management unit. 7.2 L hydrogen is stored in a Class IV composite cylinder at 300 bar. The case parameters are listed in Table 3, and a cost analysis is included at the end of the case study.
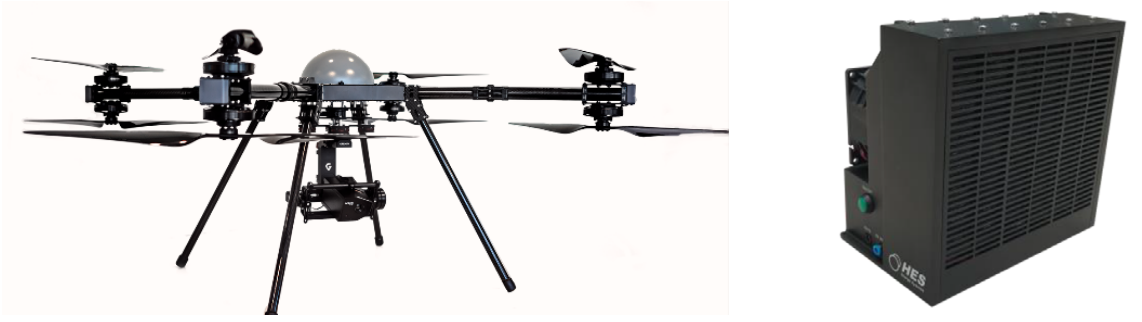

Fig. 1: Staaker BG2OO multirotor drone from Nordic Unmanned and an Aerostak fuel cell from HES 


\section{CASE RESULTS}

By going through the analysis steps from S0 to S6 using the defined case parameters (Table 3), it is found that the fuel cell powered drone will achieve a flight time of 99 minutes. That is an improvement of 43 minutes compared to when it is powered by the original $7.5 \mathrm{~kg}$ LiPo-batteries. The FCHS is heavier than the original batteries, but even a similar mass off LiPo-batteries $(12.2 \mathrm{~kg})$ will only give an endurance of 59 minutes. That is only 3 minutes more than with the original batteries. The key results from the analysis are listed in Table 4.

It should be noted that the higher take-off mass will reduce the payload capacity when trying to stay below a maximum takeoff mass of $25 \mathrm{~kg}$, and that a higher take-off mass can affect maneuverability.

Table 3. Case parameters for the Staaker BG2OO from Nordic Unmanned AS.

\begin{tabular}{|c|c|c|}
\hline Parameter & Symbol & Values \\
\hline \multicolumn{3}{|c|}{ Multirotor drone } \\
\hline Propeller diameter & $d_{\text {prop }}$ & 28 in \\
\hline Empty weight & $m_{E W}$ & $8.5 \mathrm{~kg}$ \\
\hline LiPo-battery mass & $m_{\text {batt }}$ & $7.5 \mathrm{~kg}$ \\
\hline LiPo-battery capacity & $E_{\text {batt }}$ & 1136 Wh (32Ah@44.4V, $\left.\eta_{D O D}=80 \%\right)$ \\
\hline \multicolumn{3}{|c|}{ Hybrid Fuel Cell System } \\
\hline Fuel cell power & $P_{F C}$ & $2000 \mathrm{~W}$ \\
\hline Hybrid battery power & $P_{h . b a t t}$ & $400 \mathrm{~W}$ \\
\hline Degree of hybridization & $\beta_{\text {batt }}$ & 0.17 \\
\hline Energy buffer for emergency landing & $t_{e m c}$ & 2 min $(@ 2.4$ kW) \\
\hline Mass of FC system & $m_{F C}$ & $4.4 \mathrm{~kg}$ \\
\hline Mass of $7.2 \mathrm{~L} \mathrm{H}_{2}$ cylinder & $m_{\mathrm{H}_{2}}$ & $4.0 \mathrm{~kg}$ \\
\hline
\end{tabular}

Table 4. Results from the case with a fuel cell hybrid system w/7.2 L Hydrogen at 300 bar

\begin{tabular}{|r|c|c|c|c|c|c|}
\hline Ref. & Results & Sym. & LiPo ref. & FCHS $[7.2 \mathrm{~L} @ 300$ bar $]$ & Diff. & $\%$ \\
\hline S1 & Effective energy & $E$ & $1136 \mathrm{Wh}$ & $2954 \mathrm{Wh}$ & $+1817 \mathrm{Wh}$ & $+160 \%$ \\
\hline S2 & Mass energy system & $m_{E}$ & $7.5 \mathrm{~kg}$ & $12.2 \mathrm{~kg}$ & $+4.7 \mathrm{~kg}$ & $+62.6 \%$ \\
\hline S2 & Take-off mass & $m_{\text {TOM }}$ & $16 \mathrm{~kg}$ & $20.7 \mathrm{~kg}$ & $+4.7 \mathrm{~kg}$ & $+29.5 \%$ \\
\hline S3 & Specific energy & $\varepsilon_{S}$ & $144 \mathrm{Wh} \cdot \mathrm{kg}^{-1}$ & $242 \mathrm{Wh} \cdot \mathrm{kg}^{-1}$ & $+98 \mathrm{Wh} \cdot \mathrm{kg}^{-1}$ & $+68 \%$ \\
\hline S4 & Propulsion power & $P_{\text {TOM }}$ & $1215 \mathrm{~W}$ & $1791 \mathrm{~W}$ & $+575.8 \mathrm{~W}$ & $+64.6 \%$ \\
\hline S5 & Endurance & $t_{e}$ & $56.1 \mathrm{~min}$ & $98.9 \mathrm{~min}$ & $+42.8 \mathrm{~min}$ & $+76.3 \%$ \\
\hline
\end{tabular}

\section{ENDURANCE PLOT AND ANALYSIS}

By using the endurance model, a plot can be established that simplifies performance comparison between various power systems and system configurations. In Fig. 2, the FCHS performance with the cylinders in Table 1 is presented together with a LiPobattery reference curve. The threshold for where a FCHS will give better performance than LiPo-batteries is at $7.3 \mathrm{~kg}$. Above that mass, a FCHS will give a better endurance. 
From the battery graph, it can be seen that the endurance increases rapidly with battery size until the threshold of $7.3 \mathrm{~kg}$. Above this, the performance is only marginally improved with increasing battery size, and it tends to converge towards 60 minutes. The specific energy of batteries remains constant, and therefore does not scale well above this threshold. In that region the power consumption increases with the added mass so most of the added energy is consumed. To increase the endurance, more energy must be added without adding much more mass. This is where fuel cell hybrid systems have an advantage.

A fuel cell hybrid system has a high self-weight before any hydrogen storage is added (which contains most of the energy). But from that point, all increase in mass is related to increase in energy storage, and the specific energy of the energy system increases rapidly. Thus, a small increase in mass will give a large increase in stored energy, and even a $3 \mathrm{~L}$ hydrogen cylinder would give a higher endurance than LiPo-batteries.

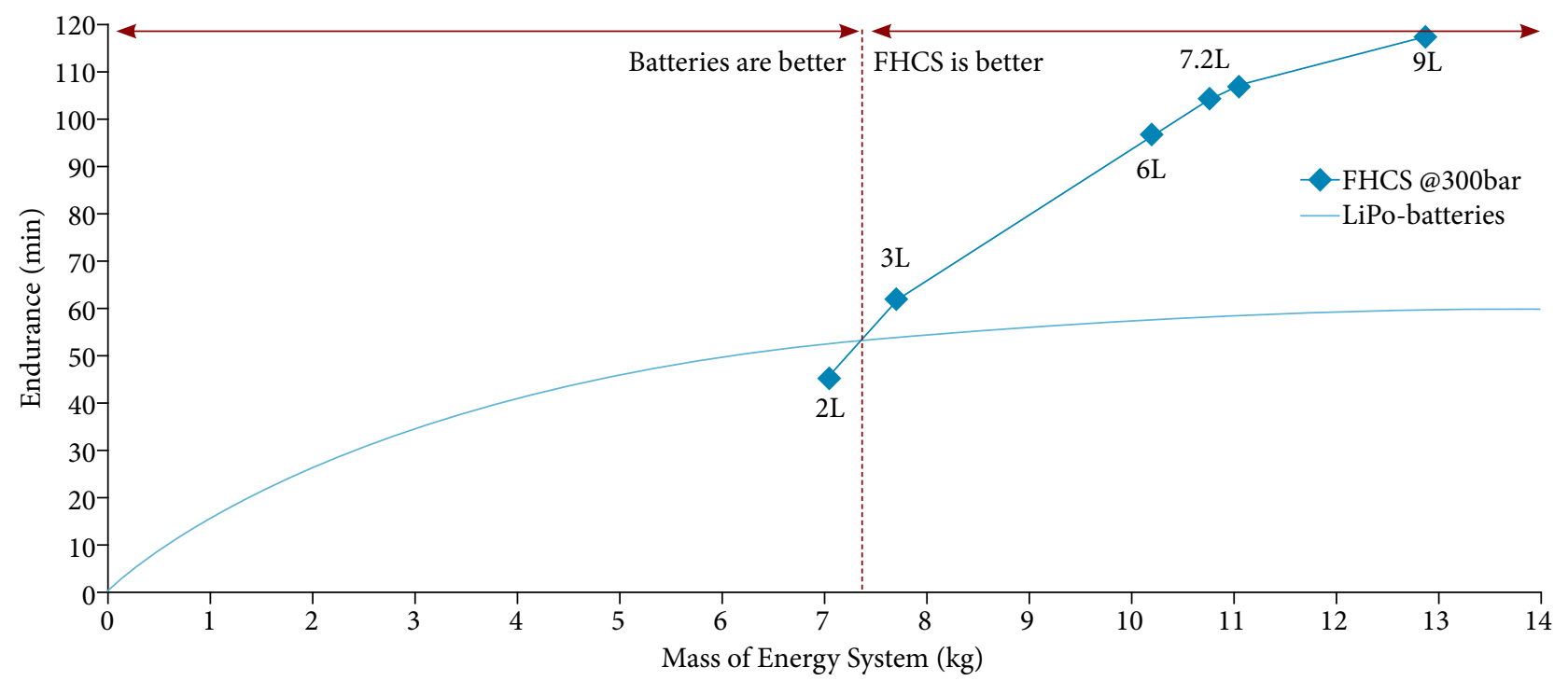

Fig. 2: Endurance plot for various power sources as a function of system mass. Note that a minimum battery mass is required to provide sufficient power to take off.

The threshold and relative performance will vary depending on the characteristics of the specific drone in question. The main factors is the power requirement of the drone, the weight sensitivity of the propulsion system, and the mass of a suitable fuel cell hybrid system. Because of the low power density of fuel cells, batteries are generally the only viable option for small multirotor drones. However, when multirotor drones and their energy source reaches a certain size and mass, fuel cell hybrid systems can become an attractive alternative. Further research could analyze the threshold for various drone sizes and FCHS characteristics.

\section{COST ANALYSIS}

Taking basis in the above case, this analysis considers the direct cost factors related to each of the energy systems. It is assumed that all required infrastructure is available and the cost of electricity is neglected.

As FCHS are not off-the-shelf components, the cost is highly affected by order volumes, degree of customization, technology developments, certification requirements, and commercial strategies. Because prices are provided on a case-to-case basis, they are also confidential. The experience of the authors is, however, that the cost of a typical FCHS that is similar to the system defined in the case study can be in the range of $€ 30-50000$. The warranty guaranteed durability can be from 500 to 1000 hours, even though the design-durability for some systems is 3000 hours. Based on this, a reasonable estimate is a fixed system cost of $€ 40$ per hour.

The variable cost is related to the hydrogen consumption. One 7.2 L tank at 300 bar contains $150 \mathrm{~g}$ of hydrogen, which has a cost of about $€ 18$ when supplied by an industrial gas supplier in Norway. For an endurance of 99 minutes, that gives $€ 11$ per hour. Thus, the direct cost of a fuel cell hybrid system is $€ 51$ per hour. 
For reference, the cost of the LiPo-batteries from the case is about $€ 2000$. At a depth-of-discharge of $80 \%$, a typical cycle life of 500 cycles can be assumed (Dogger et al., 2011). With the estimated 56 minutes endurance, that gives 467 flight hours and a cost of $€ 4.30$ per hour.

Thus, the cost of using a fuel cell hybrid system is about 12 times that of using traditional LiPo-batteries. This is considered to be a conservative estimate and the numbers are expected to improve when they become off-the-shelf components, and the availability and price of hydrogen improves. A complete return-on-investment analysis will have to include all costs related to the multirotor drone, infrastructure, training, logistics, maintenance - and quantify the operational advantage. For some cases, the added endurance from using a FCHS might enable certain operations where endurance and range is critical, significantly improving the value proposition.

It should be noted that the durability and cycle life of both energy systems depends greatly on how they are used and stored. There is also a time limit of one year for some fuel cells, where the warranty will expire and they need to be serviced. If they are not frequently used, open-cathode fuel cells need to be conditioned by being operated at about 60-70\% power for 1-2 hours every month to maintain membrane hydration. That requires man-hours, hydrogen, and some additional infrastructure that must be considered.

\section{DISCUSSION}

\section{VALIDITY OF THE MODEL}

Efforts have been made to make a simple model that is easy to apply, while still capturing the parameters that have the largest effect on the endurance. It assumes stationary hovering and an average power consumption. The intention of the model is to provide a relative performance comparison between system configurations and to indicate if a fuel cell hybrid system will provide better endurance than with batteries for a specific multirotor drone. For this intended purpose, the validity is considered to be adequate.

If the objective, however, is detailed system optimization or accurate endurance estimates, the model should be further improved. More advanced models can be based on actual mission profiles and simulate various dynamic effects that influence power consumption and the overall system efficiency. These models will include more parameters, which might not be known in the early phases of system design, and they can introduce some uncertainty. Thus, the design stage and scope of the analysis will determine the most appropriate model and level of detail to be used.

\section{MODEL IMPROVEMENTS}

For fixed-wing UAVs, it is common to use the range and endurance models outlined by Traub (2011). Hovenburg et al. (2017) carry out a sensitivity analysis to quantify the impact of system mass, altitude, and speed on the endurance and range. Donateo et al. (2017) simulated the $\mathrm{H}_{2}$ consumption and state of charge along a pre-defined mission profile and found that the net endurance from a detailed model was lower than what the simpler gross endurance estimate suggested, demonstrating the value of more detailed models for accurate estimates.

There are different approaches to modeling the power consumption of multirotor drones. They can be based on basic dynamics (Powers et al., 2015) and energy calculations, empirical models, or theoretical models. If the exact propulsion system is known, experimental data can be used to establish an accurate relation between the thrust and propulsion power consumption. A model by Hwang et al. (2018) considers system mass, efficiency, battery discharge, and drag for steady-level flight and hovering to predict the endurance for a flight path with defined distances, flight speeds, and hovering time. Liu et al. (2017) presents a theoretical power consumption model, estimates the parameters, and validates the model through test flights. Two additional models are presented by Abdilla et al. (2015) and Gatti and Giulietti (2013). External environmental factors are also of interest to model. Scicluna et al. (2019) investigated the impact of wind in hovering and found that it actually can improve the endurance. The above models for multirotor drones assume batteries as the power source. Future research can combine their approaches with FCHS models to achieve a higher accuracy than the model presented in this paper. 


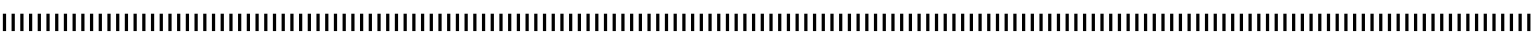

Ustolin and Taccani (2018) present an alternative approach to identify the best power source. They calculate the energy required for a multirotor drone with a defined take-off mass to complete a particular mission profile. In their case, they found that 1089 Wh was needed for a $7 \mathrm{~kg}$ drone to complete a 120 minutes flight profile. A $500 \mathrm{~W}$ fuel cell hybrid system would weigh $4.4 \mathrm{~kg}$, which was $30 \%$ less than batteries would. Thus, they concluded that the fuel cell hybrid system was the best option.

This approach will identify the most lightweight system, but that is not necessarily the same as having the best endurance. A fuel cell hybrid system with a higher specific energy than batteries can give a better endurance even though the take-off mass is higher, as demonstrated in this paper. Their approach does not capture this because the take-off mass and endurance are assumed up-front, and changes in the take-off mass and their effect on the actual endurance are not calculated.

\section{SYSTEM OPTIMIZATION AND TECHNICAL IMPROVEMENTS}

Currently, there are not many high-power lightweight fuel cells for multirotor drones on the market, and there is still room for improvement to make such systems even more competitive to batteries. To optimize the performance of a fuel cell powered multirotor drone in general, the power consumption must be reduced, and the available energy must be increased. The power consumption can be minimized by improving the efficiency of the propulsion system and by reducing mass. The self-weight of the fuel cell hybrid system is especially important and should be as low as possible. The available energy can be increased by improving the fuel cell efficiency and increasing the amount of stored hydrogen through optimizing the hydrogen storage. A breakdown of component weight and power loss could be a useful tool for targeting optimization efforts, as presented in one paper for a fixed-wing UAV (Bradley et al., 2007).

The model presented in this paper can be used in optimization to quantify the impact of various system parameters. An improved version of this model can be used to optimize the fuel cell hybrid system for specific mission profiles and to identify operational limitations.

More technical improvements related to fuel cells for UAVs were identified in a paper by Gong and Verstraete (2017), outlining the status and research needs. They recommend further research into hydrogen storage and on-site refueling, the impact of altitude on the performance of the fuel cell, water management for non-humidified operation, operational robustness, and hybridization. The latter is especially important for multirotor drones because it has a large impact on the system mass and the dynamic response. One promising approach to improve hybrid systems is to use a supercapacitor, as demonstrated by Gong et al. (2018).

\section{USE OF FC POWERED DRONE IN OPERATIONS}

Moving from an initial assessment of the feasibility for using a fuel cell hybrid system to practical application, there are a few aspects to consider. In terms of structural integration, any impact on the center of gravity will affect the stability and maneuverability (Lapeña-Rey et al., 2017). They also outline thermal management as a challenge. Considering evaporation at the cathode, the net heat generated by a $2 \mathrm{~kW}$ PEM fuel cell is about $1.6 \mathrm{~kW}$ (Larminie and Dicks, 2003). The operating temperature of such fuel cells is about $80^{\circ} \mathrm{C}$ (O'Hayre et al., 2016), and the thermal management system must maintain this temperature throughout the flight envelope. Failure to do so can cause membrane de-hydration and performance degradation. Environmental conditions such as ambient air temperature and humidity have a large impact, and a typical acceptable operating temperature range is 5 - $40{ }^{\circ} \mathrm{C}$. This is a topic that is relevant for further research because it has an important impact on the durability and the operating envelope.

Looking beyond endurance, cost and lifecycle performance will also be important to consider (Belmonte et al., 2018). The inherent safety challenges associated with hydrogen must be addressed, and suitable regulations for safe integration and operation of such systems must be developed (Sisco and Robinson, 2019). The latter is especially important for more wide scale adoption of fuel cell powered drones. 


\section{CONCLUSION}

A model for analyzing and quantifying the potential of using a hybrid fuel cell system on a multirotor drone is presented. The model can be used to identify if a fuel cell hybrid system will give a better endurance than when powered by LiPobatteries. The model is applied to a case and to create an endurance plot, demonstrating the value of the model. A fuel cell hybrid system will not always be a viable option for multirotor drones, but for certain sizes of multirotor drones, they can provide a performance advantage. Further analysis of the threshold for various drone sizes and FCHS characteristics is recommended.

In the case of an X8 multirotor drone with MTOM of $25 \mathrm{~kg}$, a FCHS with a 7.2 L hydrogen cylinder at 300 bar will give a 43 minutes improvement of the endurance, a $76 \%$ increase compared to the reference batteries. A cost analysis estimates the cost of a fuel cell hybrid system to be about 12 that of LiPo-batteries, assuming the current state of technology.

Future research could improve the validity of the propulsion-power model. By improving the model to account for the dynamic effects from a specific mission profile, more advanced system design and optimization can be carried out. The models should be verified with experimental data. For operations, it will be important to know the maneuvering freedom like maximum range, and optimal cruise and maneuvering velocities. The impact of environmental conditions on fuel cell performance, degradation mechanisms and durability is a highly relevant topic. Finally, identifying potential barriers for further adoption of FC-powered multirotor drones, how the technology can be improved and optimized, and how the return-on-investment figures can be improved will also be of interest to the research community and the industry.

\section{AUTHOR'S CONTRIBUTION}

Conceptualization: Apeland J, Pavlou D and Hemmingsen T; Methodology: Apeland J; Investigation: Apeland J; Writing - Original Draft: Apeland J; Writing - Review \& Editing: Apeland J, Pavlou D and Hemmingsen T; Supervision: Pavlou D, Hemmingsen $\mathrm{T}$ and Fagertun $\mathrm{O}$.

\section{ACKNOWLEDGMENTS}

Editors and authors are thankful to Fundação Conrado Wessel for providing the financial support for publishing this article.

\section{FUNDING}

The Research Council of Norway

[http://doi.org/10.13039/501100005416]

Grant \#286603

Nordic Unmanned AS

\section{REFERENCES}

Abdilla A, Richards A and Burrow S (2015) Power and endurance modelling of battery-powered rotorcraft. 2015 IEEE/RSJ International Conference on Intelligent Robots and Systems (IROS). 675-680. https://doi.org/10.1109/IR0S.2015.7353445 
Barrett S (2017) EnergyOr fuel cell powered multirotor for French Air Force. Fuel Cells Bulletin 2017 (1): 4. https://doi.org/10.1016/ S1464-2859(17)30008-1

Barrett S (2018a) HES multirotor drone, designed and built in US, has 3h flight time. Fuel Cells Bulletin 2018 (12): 5. https://doi. org/10.1016/S1464-2859(18)30446-2

Barrett S (2018b) Intelligent Energy unveils 800 W fuel cell for commercial UAVs. Fuel Cells Bulletin 2018 (10): 6. https://doi. org/10.1016/S1464-2859(18)30363-8

Barrett S (2019a) HES Hycopter drone highlighted by Dubai Police at Intersec 2019. Fuel Cells Bulletin 2019 (2): 6. https://doi. org/10.1016/S1464-2859(19)30053-7

Barrett S (2019b) Intelligent Energy launches 2.4 kW fuel cell module for UAVs. Fuel Cells Bulletin 2019 (5): 6. https://doi.org/10.1016/ S1464-2859(19)30189-0

Barrett S (2019c) Intelligent Energy powers two multirotor UAVs to new records. Fuel Cells Bulletin 2019 (2): 5-6. https://doi. org/10.1016/S1464-2859(19)30051-3

Belmonte N, Staulo S, Fiorot S, et al. (2018) Fuel cell powered octocopter for inspection of mobile cranes: Design, cost analysis and environmental impacts. Applied Energy 215 (1): 556-565. https://doi.org/10.1016/j.apenergy.2018.02.072

Boukoberine MN, Zhou Z and Benbouzid M (2019) A critical review on unmanned aerial vehicles power supply and energy management: Solutions, strategies, and prospects. Applied Energy 255 (1). https://doi.org/10.1016/j.apenergy.2019.113823

Bradley TH, Moffitt BA, Fuller TF, et al. (2009a) Comparison of Design Methods for Fuel-Cell-Powered Unmanned Aerial Vehicles. Journal of Aircraft 46(6): 1945-1956. https://doi.org/10.2514/1.41658

Bradley TH, Moffitt BA, Mavris D, et al. (2009b) APPLICATIONS - TRANSPORTATION | Aviation: Fuel Cells. In: Garche J (ed) Encyclopedia of Electrochemical Power Sources. Amsterdam: Elsevier, 186-192.

Bradley TH, Moffitt BA, Mavris DN, et al. (2007) Development and experimental characterization of a fuel cell powered aircraft. Journal of Power Sources 171(2): 793-801. https://doi.org/10.1016/j.jpowsour.2007.06.215

CEN (2002) Transportable gas cylinders - Fully wrapped composite cylinders.

Dell RM, Rand DAJ and Connor P (2001) Lithium Batteries. Understanding Batteries. Cambridge, UK: Royal Society of Chemistry.

Dogger JD, Roossien B and Nieuwenhout FDJ (2011) Characterization of Li-lon Batteries for Intelligent Management of Distributed Grid-Connected Storage. IEEE Transactions on Energy Conversion 26(1): 256-263. https://doi.org/10.1109/ TEC.2009.2032579

Donateo T, Ficarella A, Spedicato L, et al. (2017) A new approach to calculating endurance in electric flight and comparing fuel cells and batteries. Applied Energy 187(1): 807-819. https://doi.org/10.1016/j.apenergy.2016.11.100

Gatti M and Giulietti F (2013) Preliminary Design Analysis Methodology for Electric Multirotor. IFAC Proceedings Volumes 46(30): 58-63. https://doi.org/10.3182/20131120-3-FR-4045.00038

Gong A, Palmer JL and Verstraete D (2018) Flight Test of a Fuel-Cell/Battery/Supercapacitor Triple Hybrid UAV Propulsion System. 31st Congress of the International Council of the Aeronautical Sciences.

Gong A and Verstraete D (2017) Fuel cell propulsion in small fixed-wing unmanned aerial vehicles: Current status and research needs. International Journal of Hydrogen Energy 42(33): 21311-21333. https://doi.org/10.1016/j.ijhydene.2017.06.148

Hovenburg AR, Johansen TA and Storvold R (2017) Mission performance trade-offs of battery-powered sUAS. 2017 International Conference on Unmanned Aircraft Systems (ICUAS). 601-608. http://dx.doi.org/10.1109/ICUAS.2017.7991389

Hwang M-h, Cha H-R and Jung S (2018) Practical Endurance Estimation for Minimizing Energy Consumption of Multirotor Unmanned Aerial Vehicles. Energies 11(9):2221

Lapeña-Rey N, Blanco JA, Ferreyra E, et al. (2017) A fuel cell powered unmanned aerial vehicle for low altitude surveillance missions. International Journal of Hydrogen Energy 42 (10): 6926-6940. https://doi.org/10.1016/j.ijhydene.2017.01.137

Larminie $J$ and Dicks A (2003) Efficiency and Open Circuit Voltage. Fuel cell systems explained. 2nd ed. Chichester: Wiley.

Leishman JG and Ananthan S (2006) Aerodynamic optimization of a coaxial proprotor. Annual Forum Proceedings-American Helicopter Society. Phoenix: American Helicopter Society, INC.

Lemmon EW, Huber ML and Leachman JW (2008) Revised Standardized Equation for Hydrogen Gas Densities for Fuel Consumption Applications. Journal of Research of the national Institute of Standards and Technology 113 (6): 341-350. https://doi.org/ 10.6028/ jres. 113.028

Liu Z, Sengupta R and Kurzhanskiy A (2017) A power consumption model for multi-rotor small unmanned aircraft systems. 2017 International Conference on Unmanned Aircraft Systems (ICUAS). 310-315. https://doi.org/10.1109/ICUAS.2017.7991310 
Mi C and Masrur MA (2018a) Electric Energy Sources and Storage Devices. Hybrid Electric Vehicles: Principles and Applications with Practical Perspectives. Newark, UK: John Wiley \& Sons, Incorporated.

Mi C and Masrur MA (2018b) HEV Fundamentals. Hybrid Electric Vehicles: Principles and Applications with Practical Perspectives. Newark, UK: John Wiley \& Sons, Incorporated.

Nishizawa A, Kallo J, Garrot 0, et al. (2013) Fuel cell and Li-ion battery direct hybridization system for aircraft applications. Journal of Power Sources 222 (15): 294-300. https://doi.org/10.1016/j.jpowsour.2012.09.011

O'Hayre R, Cha S-W, Colella WG, et al. (2016) Fuel Cell Fundamentals, New Jersey: John Wiley \& Sons.

Powers C, Mellinger D and Kumar V (2015) Quadrotor Kinematics and Dynamics. In: Valavanis KP and Vachtsevanos GJ (eds) Handbook of Unmanned Aerial Vehicles. Springer Netherlands : Imprint: Springer.

Scicluna L, Sant T and Farrugia RN (2019) Investigation of wind flow conditions on the flight endurance of UAVs in hovering flight: A preliminary study. ASME 2019 2nd International Offshore Wind Technical Conference. https://doi.org/ 10.3390/drones2040043

Sisco J and Robinson P (2019) Fuel Cell Powered UAS: Hydrogen Safety, Handeling, and Field Experience. AUVSI Xponential. Chicago.

Traub LW (2011) Range and Endurance Estimates for Battery-Powered Aircraft. Journal of Aircraft 48 (2): 703-707. https://doi. org/10.2514/1.C031027

Ustolin F and Taccani R (2018) Fuel cells for airborne usage: Energy storage comparison. International Journal of Hydrogen Energy 43 (26): 11853-11861. https://doi.org/10.1016/j.ijhydene.2018.04.017

Verstraete D, Lehmkuehler K, Gong A, et al. (2014) Characterisation of a hybrid, fuel-cell-based propulsion system for small unmanned aircraft. Journal of Power Sources 250 (15): 204-211. https://doi.org/10.1016/j.jpowsour.2013.11.017 